\title{
Effects of ripple cross angles and turbulence models on wet curtain resistance
}

\author{
Tao Ding ${ }^{1}$, Lumeng Fang ${ }^{1,2}$, Zhengxiang Shi ${ }^{1,3^{*}}$, Baoming $\mathrm{Li}^{1,3}$, Yang Zhao ${ }^{1,2}$ \\ (1. College of Water Resources and Civil Engineering, China Agricultural University, Beijing 100083, China; \\ 2. Beijing Engineering Research Center for Safety and Energy-Saving Technology for Water Supply Network Systems, Beijing 100083, \\ China; 3. Key Laboratory of Agricultural Engineering in Structure and Environment, Beijing 100083, China)
}

\begin{abstract}
To study the influence of ripple cross angles on the resistance of wet curtains, wet curtains with different ripple cross angles $\left(45^{\circ} / 45^{\circ}, 45^{\circ} / 15^{\circ}\right)$ were tested on agricultural ventilation equipment performance testing benches, and the static pressure drop under different wind speeds $(1-3 \mathrm{~m} / \mathrm{s}$ ) was determined. Four turbulence models $(\kappa-\varepsilon$, RNG $\kappa-\varepsilon, \kappa-\omega$, SST $\kappa-\omega)$ were adopted for numerical simulations of the two types of wet curtain, and the simulations' results were compared with those of experiments. The average errors found are $41.1 \%, 48.7 \%, 27.1 \%$, and $27.8 \%$, respectively, and the $\kappa-\omega$ model is found to be the most suitable one for the calculation of wet curtain resistance among the four turbulence models. By using the $\kappa-\omega$ turbulence model, the static pressure drop performances of wet curtains with ripple cross angles $45^{\circ} / 35^{\circ}$ and $45^{\circ} / 25^{\circ}$ were calculated. Resistance increases with wind speed and ripple cross angles, and a large ripple cross angle has a higher resistance growth rate with increasing wind speed.
\end{abstract}

Keywords: wet curtain, ripple cross angle, resistance, turbulence model, ventilation, cooling and humidifying system DOI: $10.25165 / j . i j a b e .20191204 .3446$

Citation: Ding T, Fang L M, Shi Z X, Li B M, ZhaoY. Effects of ripple cross angles and turbulence models on wet curtain resistance. Int J Agric \& Biol Eng, 2019; 12(4): 43-46.

\section{Introduction}

A wet curtain is formed by the bonding of fiber paper with a specific corrugated cross angle in which the adjacent layers of cooling pad paper of the wet curtain are placed in opposite directions. This placement enables full access to air and water and strengthens the processes of heat and mass transfer. A wet curtain cooling system consists of a wet curtain, fans, a water circulating system, and a control system. A cooling pad is mounted on the wall at one end of the greenhouse, and the fan is mounted on the other end of the wall. Exhaust air flowing outwards creates negative pressure in the greenhouse, thereby forcing outside air into the room. The water that flows down from the wet screens comes in contact with air at the surface of the wet curtains. For cooling and humidification, the sensible heat from the air is used to evaporate the water ${ }^{[1]}$. As a simple solution for cooling and humidification, the wet curtain has been widely used in agriculture and industry and has achieved good results because of its easy installation and low cost. Especially in the field of livestock, a wet curtain cooling system can effectively change the ambient conditions when used in combination with the ventilation facility, reduce temperature and improve climate control ${ }^{[2-4]}$.

Received date: 2018-04-24 Accepted date: 2019-06-21

Biographies: Tao Ding, Assistant Professor , research interest: agricultural bioenvironment and energy engineering, Email: dingtao@cau.edu.cn; Lumeng Fang, Master candidate, research interest: hydrodynamics, Email: fanglumeng@ cau.edu.cn; Baoming Li, Professor, research interest: agricultural bioenvironment and energy engineering, Email: libm@cau.edu.cn; Yang Zhao, Master candidate, research interest: hydrodynamics, Email: zhaoyangcau@163.com.

*Corresponding author: Zhengxiang Shi, Professor, research interest: agricultural bioenvironment and energy engineering. P.O.Box 58, No.17, Qinghua East Road, Haidian District, Beijing 100083, China. Tel: +86-10-61737570, Fax: +86-10-61737570, Email: shizhx@cau.edu.cn.
Research on wet curtains originated in Zhou's study ${ }^{[5]}$, which included an experiment to examine the optimized structure of the paper of the wet curtains. The study summarized the correlation between efficiency, resistance, wet curtain structure and operation parameters according to the experimental results and ultimately helped optimize the structural parameters on the basis of the experimental results. The mechanical properties of the wet curtain were studied by Wang and Ding ${ }^{[6]}$. Zhang et al. ${ }^{[7]}$ and Zhang et al. ${ }^{[8]}$, who investigated the installation of wet curtains. Lu et al. ${ }^{[9]}$ and Cheng et al. ${ }^{[10]}$ conducted research on ventilation in wet curtains. Many scholars have experimentally analyzed corrugated channel characteristics and wet curtain cooling effects $^{[11-17]}$.

Owing to the rapid development of computational fluid dynamics (CFD) and business computing software, certain experimental conditions can be quickly and accurately simulated using CFD technology, which enables a more in-depth study of certain relevant content. For example, greenhouse air exchange and temperature distribution have been analyzed with $\mathrm{CFD}^{[18]}$. Several studies have used CFD to investigate the specific performance and optimization of different turbulence models, as shown in Table 1.

Table 1 Studies of the performance of different turbulence models

\begin{tabular}{cccc}
\hline Turbulence model & Research object & Index & Reference \\
\hline SST & $\begin{array}{c}\text { Staggered corrugated } \\
\text { channel }\end{array}$ & Pressure drop & Su and Zhang ${ }^{[19]}$ \\
$k-\varepsilon$ & $\begin{array}{c}\text { Fan-pad cooling system } \\
\text { in greenhouse }\end{array}$ & $\begin{array}{c}\text { Temperature and } \\
\text { wind speed }\end{array}$ & Xu et al. ${ }^{[20]}$ \\
Standard & Corrugated cellulose \\
$k$-Epsilon & evaporative cooling pads & Pressure drop & Franco, et al. ${ }^{[21]}$ \\
\hline
\end{tabular}

However, research on the resistance in wet curtain ripple current for various stagger angles has not included a qualitative and 
quantitative analysis of the relationship between the resistance and the wet curtain wind speed. Furthermore, there has been no comparison among different turbulence models with respect to the calculation of the parameter of wet curtain using CFD, and there is no clear conclusion of which model is appropriate for simulation.

By expanding on several previous studies, this research used experimental and simulation methods to study the influence of the wet curtain's change in resistance and different turbulence models on the simulation results. The goal of this study is to determine which turbulence model is most suitable for CFD simulation of the wet curtain.

\section{Materials and methods}

\subsection{Experimental study}

The property of resistance is an important performance indicator. Relatively low resistance with significant cooling power is expected in production. A drop in static pressure reflects a wet curtain's resistance property, and a larger static pressure drop represents greater resistance. The aim of this experimental study is to obtain the resistance property of wet curtains using numerical tests.

The experimental study was conducted on an agricultural ventilation equipment performance testing bench (Figure 1, Key Laboratory of the Ministry of Agriculture Engineering Facilities, College of Water Resources and Civil Engineering, China Agriculture University). The closed air chamber has a frequency-change auxiliary fan to form the conditions of wind speed. Behind the auxiliary fan, the flow is decelerated in a settling chamber, which is equipped with honeycomb strengtheners to straighten the flow. The tunnel nozzle accelerates the wind from the settling chamber to the test section, and the tilt tube micro-manometer is connected in front of and behind the nozzles to measure the air flow and static differential pressure. The closed air chamber tests air flow, resistance, current, voltage, power and other technical parameters under various static pressure conditions.

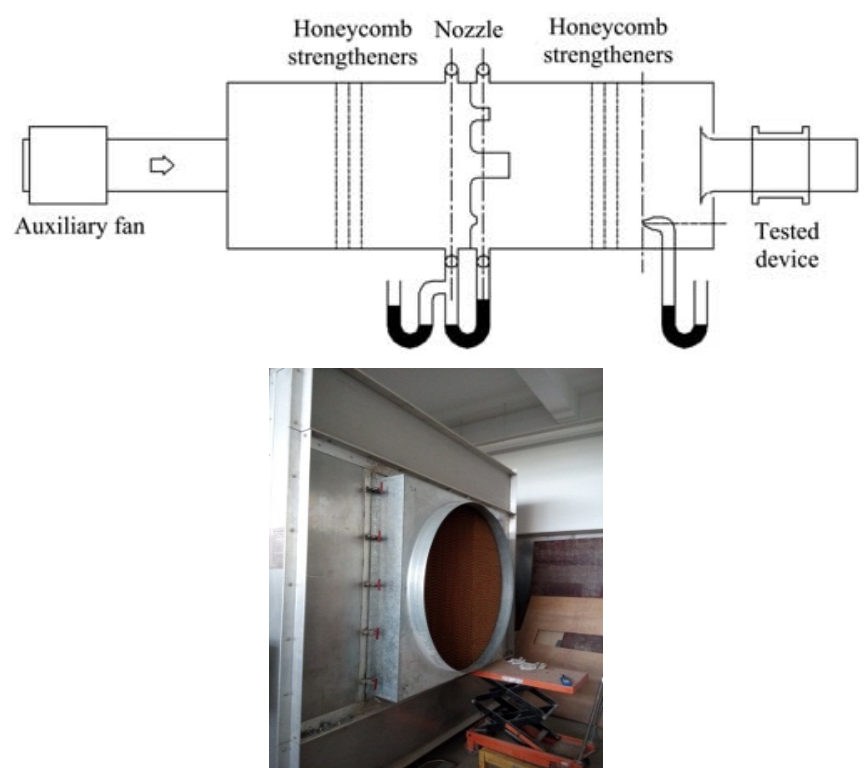

Figure 1 Agricultural ventilation equipment performance testing bench

\subsection{Numerical simulation}

In the present study, CFD was used as a powerful approach to research the aerodynamic flow field. By using commercial software, the performance of a wet curtain under different flow conditions can be predicted relatively accurately.

\subsubsection{Computational model}

The geometric shape of tested wet curtain periodically repeats along the flow direction, and the flow condition shows periodic, fully developed characteristics. To appropriately reduce the calculations required, simplified three-dimensional numerical models were created to obtain numerical results. As shown in Figure 2, the numerical models are a small piece of tested wet curtain and wavy channels of 4 layers and 2 periods, with the thickness being maintained at $150 \mathrm{~mm}$.
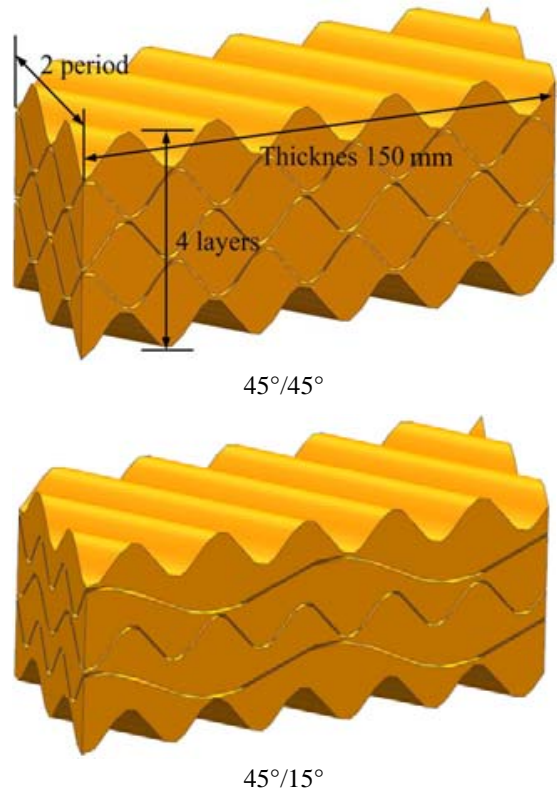

Figure 2 Computational model

\subsubsection{Computational grid}

A computational grid was created by means of ANSYS CFD, the unstructured grid was applied, and the boundary grid was locally refined for higher calculation accuracy. The three-dimensional grid of the $45^{\circ} / 45^{\circ}$ model, for example, is presented in Figure 3. During the simulation, the boundary conditions were set as the following: in the thickness direction, one side is the velocity inlet, adopting the tested wind speed in Table 2, the other side is the pressure outlet, where static pressure equals normal atmosphere; and in the period direction, the two sides display translational periodicity.

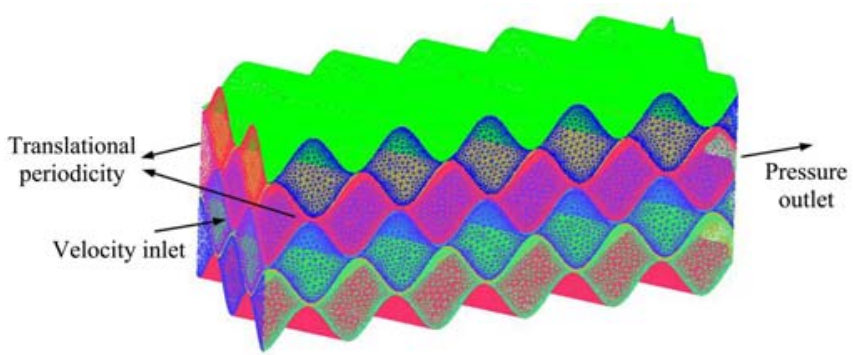

Figure 3 Computational grid

\section{Results and discussion}

\subsection{Test results}

The test objects are two types of wet curtain with different ripple cross angles $\left(45^{\circ} / 45^{\circ}, 45^{\circ} / 15^{\circ}\right)$. The average height of the wavy channel is $6.7 \mathrm{~mm}$, and the thickness is $160 \mathrm{~mm}$. During the test, the wind speed was made to vary from $1 \mathrm{~m} / \mathrm{s}$ to $3 \mathrm{~m} / \mathrm{s}$ by controlling the auxiliary fan rotational speed. Thus, Reynolds numbers, as calculated with wind speed and equivalent diameter of wavy channel $D_{e}$, vary between 600 and 1300 . $D_{e}$ can be defined as: 


$$
D_{e}=\frac{4 V}{A_{d}}
$$

where, $V$ is the volume of one cycle of the wavy channel and $A_{d}$ is the heat transfer area of one cycle of the wavy channel. Thus, the Reynolds number during the tests varied between 400 and 800 . The static pressure drop, $P_{s}$, under each wind speed condition was measured, and the test results for wet curtains of $45^{\circ} / 45^{\circ}$ and $45^{\circ} / 15^{\circ}$ are shown in Table 2 .

Table 2 Test results of static pressure drop

\begin{tabular}{|c|c|c|c|}
\hline \multicolumn{2}{|c|}{$45^{\circ} / 45^{\circ}$} & \multicolumn{2}{|c|}{$45^{\circ} / 15^{\circ}$} \\
\hline $\begin{array}{l}\text { Wind speed } \\
\qquad / \mathrm{m}^{-1} \cdot \mathrm{s}^{-1}\end{array}$ & $\begin{array}{l}\text { Static pressure drop } \\
\qquad / \mathrm{Pa}\end{array}$ & $\begin{array}{l}\text { Wind speed } \\
/ \mathrm{m} \cdot \mathrm{s}^{-1}\end{array}$ & $\begin{array}{l}\text { Static pressure drop } \\
\qquad / \mathrm{Pa}\end{array}$ \\
\hline 1.417 & 12.26 & 1.329 & 4.90 \\
\hline 1.690 & 19.61 & 1.775 & 7.36 \\
\hline 2.050 & 29.42 & 2.050 & 12.26 \\
\hline 2.483 & 44.13 & 2.429 & 19.61 \\
\hline 2.989 & 66.20 & 2.922 & 29.42 \\
\hline
\end{tabular}

3.2 Numerical simulation results and comparison with test results

All computations were performed with the business software CFX. Steady three-dimensional calculation was carried out. The turbulence models are $\kappa-\varepsilon, \kappa-\omega$, RNG $\kappa-\varepsilon$ and Shear Stress Transport (SST), and the discretization scheme for the momentum equation is first order upwind. The convergence residual is approximately $10^{-6}$. Results for the $45^{\circ} / 45^{\circ}$ and $45^{\circ} / 15^{\circ}$ wet curtains are shown in Tables 3 and 4 . We define the relative error

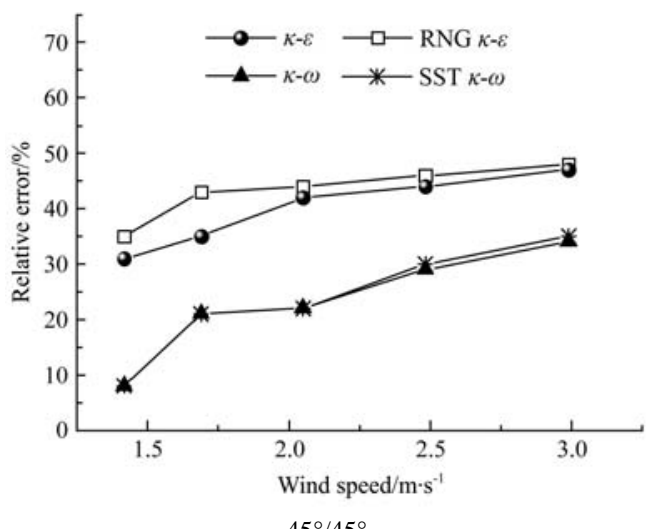

Figure 4 Relative error of four turbulence models

Under these calculation conditions, most of the obtained results of static pressure drop are lower than the experimental data. A possible reason for this finding may be that the numerical simulation did not appropriately consider the friction drag and other forms of loss. The relative errors increase with wind speed when the speed is low and gradually become stable when the speed increases. For these four turbulence models $(\kappa-\varepsilon$, RNG $\kappa-\varepsilon, \kappa-\omega$, SST $\kappa-\omega)$, compared with the experimental data, the average numerical errors of two $45^{\circ} / 45^{\circ}$ and $45^{\circ} / 15^{\circ}$ wet curtains are $41.1 \%, 48.7 \%, 27.1 \%$, and $27.8 \%$, respectively. The $\kappa-\omega$ and SST $\kappa-\omega$ turbulence models performed significantly better than the $\kappa-\varepsilon$ and RNG $\kappa-\varepsilon$ turbulence models. The results of the $\kappa-\omega$ and SST $\kappa$ - $\omega$ turbulence models are notably similar, and the $\kappa-\omega$ turbulence model is slightly better.

Hence, this study adopted the $\kappa$ - $\omega$ turbulence model for numerical simulation of wet curtain ripple cross angles of $45^{\circ} / 35^{\circ}$ and $45^{\circ} / 25^{\circ}$ to estimate the static pressure drop. The numerical results are shown in Table 5 . The static pressure drop as the percentage of the experimental value minus the numerical value, divided by the experimental value. The relative error for the four turbulence models under calculation conditions are shown in Figure 4.

Table 3 Contrast of numerical results and experimental data for static pressure drop of $45^{\circ} / 45^{\circ}$ wet curtain

\begin{tabular}{|c|c|c|c|c|c|}
\hline \multirow{2}{*}{$\begin{array}{l}\text { Wind speed } \\
\qquad / \mathrm{m} \cdot \mathrm{s}^{-1}\end{array}$} & \multicolumn{5}{|c|}{$45^{\circ} / 45^{\circ}$ static pressure drop $/ \mathrm{Pa}$} \\
\hline & Experiment & $\kappa-\varepsilon$ & RNG $\kappa-\varepsilon$ & $\kappa-\omega$ & $\mathrm{SST} \kappa-\omega$ \\
\hline 1.417 & 12.26 & 8.48 & 8.03 & 11.29 & 11.29 \\
\hline 1.690 & 19.61 & 11.84 & 11.27 & 15.57 & 15.46 \\
\hline 2.050 & 29.42 & 17.09 & 16.43 & 22.93 & 22.84 \\
\hline 2.483 & 44.13 & 24.76 & 23.99 & 31.22 & 30.97 \\
\hline 2.989 & 66.20 & 35.23 & 34.64 & 43.86 & 43.23 \\
\hline \multicolumn{2}{|c|}{ Average relative error/\% } & 39.8 & 43.2 & 22.7 & 23.2 \\
\hline
\end{tabular}

Table 4 Contrast of numerical results and experimental data for static pressure drop of $45^{\circ} / 5^{\circ}$ wet curtain

\begin{tabular}{|c|c|c|c|c|c|}
\hline \multirow{2}{*}{$\begin{array}{l}\text { Wind speed } \\
\qquad / \mathrm{m} \cdot \mathrm{s}^{-1}\end{array}$} & \multicolumn{5}{|c|}{$45^{\circ} / 15^{\circ}$ static pressure drop $/ \mathrm{Pa}$} \\
\hline & Experiment & $\kappa-\varepsilon$ & RNG $\kappa-\varepsilon$ & $\kappa-\omega$ & $\mathrm{SST} \kappa-\omega$ \\
\hline 1.190 & 2.45 & 2.32 & 2.16 & 3.72 & 3.77 \\
\hline 1.775 & 7.36 & 4.64 & 4.40 & 7.14 & 7.26 \\
\hline 2.050 & 12.26 & 5.99 & 5.71 & 9.34 & 9.18 \\
\hline 2.429 & 19.61 & 8.12 & 7.80 & 12.34 & 12.09 \\
\hline 2.992 & 29.42 & 11.84 & 11.48 & 17.26 & 16.99 \\
\hline \multicolumn{2}{|c|}{ Average relative error/\% } & 42.4 & 54.2 & 31.4 & 32.4 \\
\hline
\end{tabular}

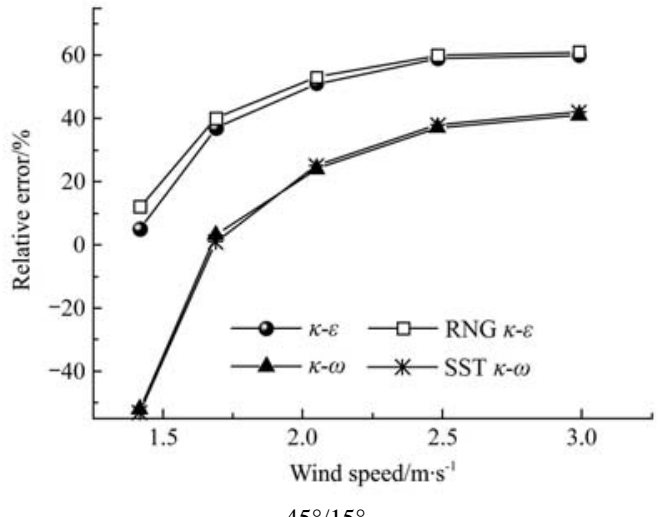

$45^{\circ} / 15^{\circ}$

performance of wet curtains with four different ripple cross angles is presented in Figure 5. The wet curtain's resistance increases with wind speed and larger ripple cross angles. The resistance growth rate of large ripple cross angles is higher with increasing wind speed. The $45^{\circ} / 45^{\circ}$ wet curtain has the greatest resistance and the highest resistance growth rate as wind speed increases.

Table 5 Numerical results for static pressure drop of $45^{\circ} / 35^{\circ}$, $45^{\circ} / 25^{\circ}$ wet curtains

\begin{tabular}{ccc}
\hline & \multicolumn{2}{c}{ Static pressure drop/Pa } \\
\cline { 2 - 3 } Wind speed $/ \mathrm{m} \cdot \mathrm{s}^{-1}$ & $45^{\circ} / 25^{\circ}$ & $45^{\circ} / 35^{\circ}$ \\
\hline 1.0 & 3.53 & 3.62 \\
1.5 & 7.00 & 7.09 \\
2.0 & 11.33 & 11.53 \\
2.5 & 16.45 & 16.99 \\
3.0 & 22.30 & 23.49 \\
\hline
\end{tabular}




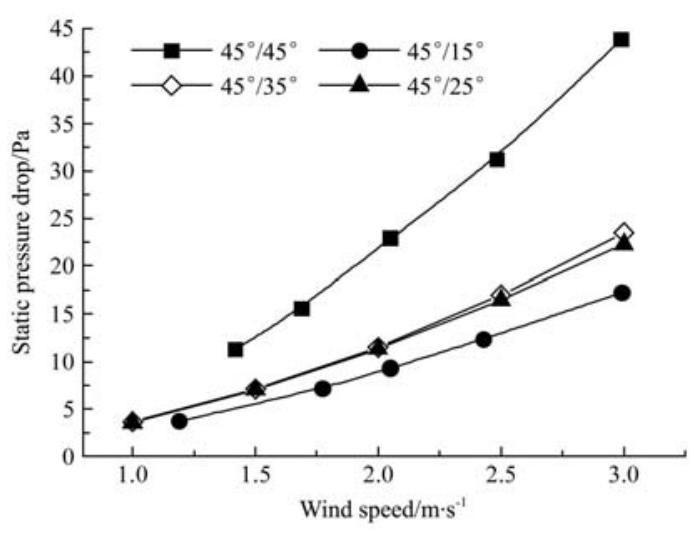

Figure 5 Static pressure drop performance of four wet curtains

\section{Conclusions}

(1) When comparing numerical calculation results with experimental data, the average errors for the four turbulence models $(\kappa-\varepsilon$, RNG $\kappa-\varepsilon, \kappa-\omega$, and SST $\kappa-\omega)$ are $41.1 \%, 48.7 \%$, $27.1 \%$, and $27.8 \%$, respectively. For the numerical simulation of wet curtain resistance, $\kappa-\omega$ and SST $\kappa$ - $\omega$ have significantly better performances than $\kappa-\varepsilon$ and RNG $\kappa-\varepsilon$; the results of the $\kappa-\omega$ and SST $\kappa$ - $\omega$ turbulence models are highly similar; and the $\kappa$ - $\omega$ turbulence model is slightly better.

(2) Within ripple cross angles from $15^{\circ}$ to $45^{\circ}$, the wet curtain resistance increases with higher wind speed and ripple cross angles. The resistance growth rate of large ripple cross angles is higher with increasing wind speed. Conclude with the optimized operational parameters for better performance.

\section{Acknowledgements}

This study was funded by the China Agricultural Research System (CARS-36), the National key research and development plan special project (2018YFF0213604) and the National Natural Science Foundation of China (31402115)

\section{[References]}

[1] Zhang M, Wang Z. Application and principle of wet-curtain cooling system in greenhouse. Journal of agricultural mechanization research, 2008; 4: 46-51. (in Chinese)

[2] Sethi V P, Sharma S K. Survey of cooling technologies for worldwide agricultural greenhouse applications. Solar Energy, 2007; 81: 1447-1459.

[3] Dagtekin M, Karaka C, Yildiz Y. Performance characteristics of a pad evaporative cooling system in a broiler house in a Mediterranean climate. Biosystems Engineering, 2009; 103: 100-104.
[4] Macmanus C N, Seth I M. A techno-economic assessment for viability of some waste as cooling pads in evaporative cooling system. Intl J Agric \& Biol Eng, 2015; 8(2): 151-158.

[5] Zhou C. Experimental study for optimal construction of honeycomb paper pad. Transactions of the CSAE, 1988; 2: 84-86. (in Chinese)

[6] Wang L, Ding X. Mechanical performance and test method for paper wet-pad. Transactions of the CSAE, 2011; 27(2): 267-271. (in Chinese)

[7] Zhang S, Song W, Teng G. Cooling effect of different installation height of wet-curtain fan-cooling system. Transactions of the CSAM, 2006; 3 : 91-94. (in Chinese)

[8] Zhang L, Huang X, Li X. Cooling performance of evaporative cooling pad-fan unit in greenhouse in Shaanxi. Journal of Xi'an Polytechnic University, 2014; 6(28): 333-328. (in Chinese)

[9] Lu Z, Wu Z, Wang M. Effects of pad and fan cooling system on necessary ventilation rate of henhouse. Chinese Journal of Animal Science, 2008; 44(23): 50-54. (in Chinese)

[10] Cheng Q, Liu J, Jin W. Effects of cooling fan-duct on cooling performance in open-sided beef barn in southern China. Transactions of the CSAE, 2014; 4(30): 126-135. (in Chinese)

[11] Egbal M A, Osama A, Mohammed A, MohdRodzi I. Performance evaluation of three different types of local evaporative cooling pads in greenhouses in Sudan. Saudi Journal of Biological Sciences, 2011; 18: 45-51.

[12] Abdollah M, Hamid R S, Mohammad L, Seyedmehdi S, Hamid B. Investigating the performance of cellulosic evaporative cooling pads. Energy Conversion and Management, 2011; 52: 2598-2603.

[13] Chung-Min L, Kun-Hung C. Wind tunnel modeling the system performance of alternative evaporative cooling pads in Taiwan region. Building and Environment, 2002; 37: 177-187.

[14] Dagtekin M, Karaka C, Yildiz Y. Performance characteristics of a pad evaporative cooling system in a broiler house in a Mediterranean climate. Biosystems Engineering, 2009; 103: 100-104.

[15] Hao X, Zhu C, Lin Y. Optimizing the pad thickness of evaporative air-cooled chiller for maximum energy saving. Energy and Buildings, 2013; 61: 146-152.

[16] Xu J, Li Y, Wang R, Liu W, Zhou P. Experimental performance of evaporative cooling pad systems in greenhouses in humid subtropical climates. Applied Energy, 2015; 138: 291-301.

[17] Li R, Poul P, Thomas L J, Svend M, Zhang G. Dynamic performance of an evaporative cooling pad investigated in a wind tunnel for application in hot and arid climate. Biosystems Engineering, 2017; 156: 173-182.

[18] Jorge F, Juan I, Montero E, Baeza J. Mechanical and natural ventilation systems in a greenhouse designed using computational fluid dynamics. Intl J Agric \& Biol Eng, 2014; 7(1): 1-16.

[19] Su W, Zhang T. Analysis of evaporative cooling mechanism of evaporative pad. Refrigeration and air conditioning, 2005; 3: 84-86.

[20] Xu F, Cai Y, Chen J. Temperature/flow field simulation and parameter optimal design for greenhouses with fan-pad evaporative cooling system. Transactions of the CSAE, 2016; 31(9): 201-208.

[21] Franco A, Valera D L, Pena A, Perez A M. Aerodynamic analysis and CFD simulation of several cellulose evaporative cooling pads used in Mediterranean greenhouses. Computers and Electronics in Agriculture, 2011; 76: 218-230. 